\title{
ANÁLISE TEMPORAL DO USO E OCUPAÇÃO DO SOLO NA BACIA DE CONTRIBUIÇÃO DO MANANCIAL DE TOCANTINS, MG.
}

\author{
Ana Carolina Nascimento Leão-anacleao@outlook.com \\ Universidade Federal de Juiz de Fora \\ Jacyara Soares Dias - jacyarasoaresdias@ hotmail.com \\ Universidade Federal de Juiz de Fora
}

Celso Bandeira de Melo Ribeiro-celso.bandeira@ufjf.edu.br

Universidade Federal de Juiz de Fora 


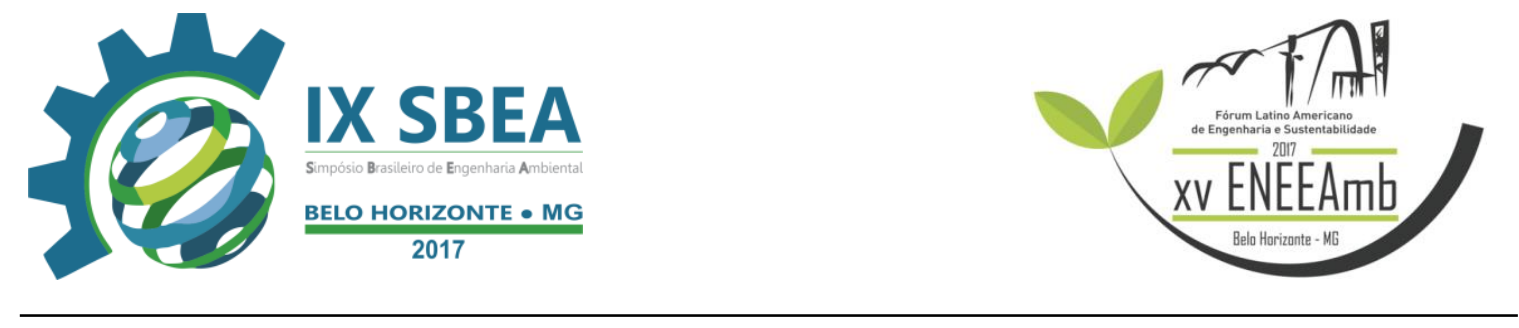

\section{RESUMO}

O presente trabalho avaliou a mudança temporal do uso e ocupação do solo da bacia de contribuição do manancial de Tocantins-mg, nos anos de 2003 e 2016, com o intuito de analisar como essas alterações afetam a bacia e as áreas de preservação permanente (APP). Utilizou-se o software Envi 5.2®para a produção das cartas de uso e ocupação do solo, com as classes pastagem, solo exposto e vegetação (matas), através de imagens Landsat 5 TM e Landsat 8 OLi, e o ArcGis 10.0®para a realização dos buffers de APP. Os resultados mostraram que no decorrer desses 13 anos houve uma relevante degradação do solo principalmente pela supressão da vegetação remanescente na área, havendo um aumento de $13 \%$ da pastagem, $4 \%$ do solo exposto e uma diminuição da vegetação em $17 \%$. Houve também uma diminuição da vegetação nas áreas de APP, em 2003 possuíam $6,10 \mathrm{~km}^{2}$ e em 2016 esse número abaixou para 3,56 km².

Palavras-chaves: Uso e ocupação do solo, monitoramento, bacia hidrográfica.

\section{INTRODUÇÃO}

A bacia hidrográfica possibilita uma abordagem integrada de vários aspectos que intervêm no uso dos recursos hídricos e na sua proteção ambiental. As transições dos aspectos do solo na maioria das vezes advindas de ações antrópicas alteram constantemente a paisagem com o passar dos anos e dentro de uma bacia hidrográfica essas modificações geram inúmeras consequências na qualidade e disponibilidade da água. Assim o gerenciamento dessas unidades reduz efeitos negativos ao meio ambiente. (PORTO, 2008)

O estudo do uso e ocupação do solo através de técnicas de sensoriamento remoto auxilia na gestão hídrica, uma vez que o uso do solo afeta a dinâmica do escoamento, infiltração e evaporação da água em uma bacia e também na qualidade da mesma em seus mananciais, pois ao percolar no solo a água adquire suas características, sendo boas ou ruins, (RIBEIRO, 2001).

LOPES et al (2010) estudou as modificações que ocorreram no uso e ocupação do solo em uma área piloto da região de vacaria, RS, utilizando técnicas de sensoriamento remoto onde constatou que $40 \%$ do campo nativo foram convertidos em 


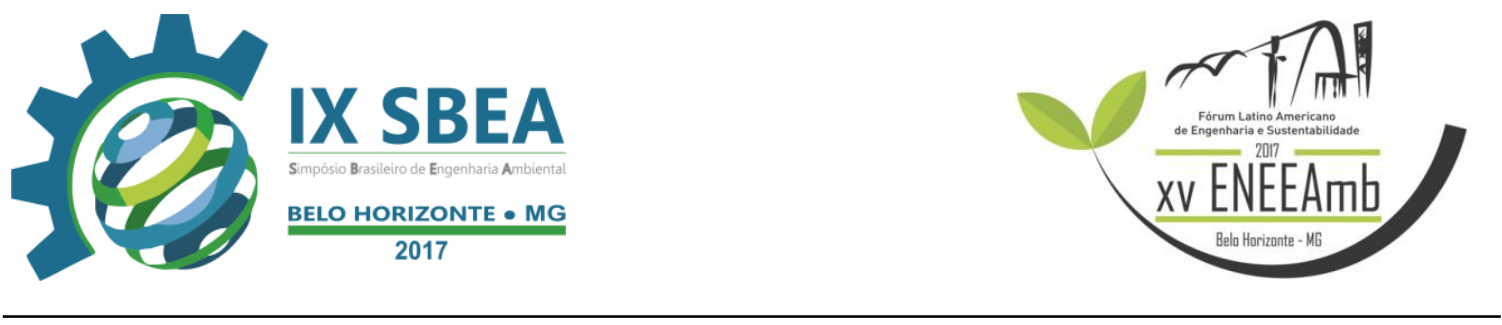

lavouras anuais e $2,3 \%$ em pomares e que a zona urbana incluída no estudo aumentou 14,0\% no 1950 e 2005, constatando que essa metodologia é fácil e viável para uma avaliação da evolução espaço-temporal do uso do solo.

Nas bacias com cobertura de floresta natural, a vegetação promove a proteção contra a erosão do solo, a sedimentação e a lixiviação excessiva de nutrientes (SOPPER, 1975), sendo essas áreas muito importantes para manter o abastecimento de água de boa qualidade. Para MARGALEF (1983), os sistemas aquáticos são receptores das descargas resultantes das várias atividades humanas nas bacias hidrográficas. A mata ciliar constitui um sistema essencial ao equilíbrio ambiental e, portanto, deve representar a preocupação central para o desenvolvimento rural sustentável.

Diante do exposto, o estudo temporal do uso e ocupação do solo é uma prática que auxilia no conhecimento da bacia hidrográfica, que é uma área dinâmica que sofre constantes modificações de acordo com o uso e ocupação de seu redor. A motivação do presente trabalho foi, portanto, mapear o uso e ocupação do solo para avaliar a sua evolução na bacia de contribuição no manancial de Tocantins - MG, no período de 2003 a 2016.

\section{MATERIAIS E MÉTODOS}

A área de estudo abrange a bacia de contribuição do manancial de Tocantins, localizada na zona rural do município, zona da mata mineira, compreendendo os distritos de Beija-Flor, Mendes e Pedra Branca, tendo o rio Paraopeba como o principal curso d'água, apresentado na Figura 1. Segundo o IBGE, a estimativa populacional da cidade apresentou-se 16.703 habitantes para o ano de 2016.

A bacia estudada possui uma área de drenagem de aproximadamente $84,4 \mathrm{~km}^{2}$ e está situada entre latitude $21^{\circ} 12^{\prime} 6,71^{\prime}$ 'S e longitude $43^{\circ} 6^{\prime} 46,34^{\prime}$ 'W. Ela é uma sub bacia do rio Paraopeba, que por sua vez é sub bacia do Rio Pomba. 


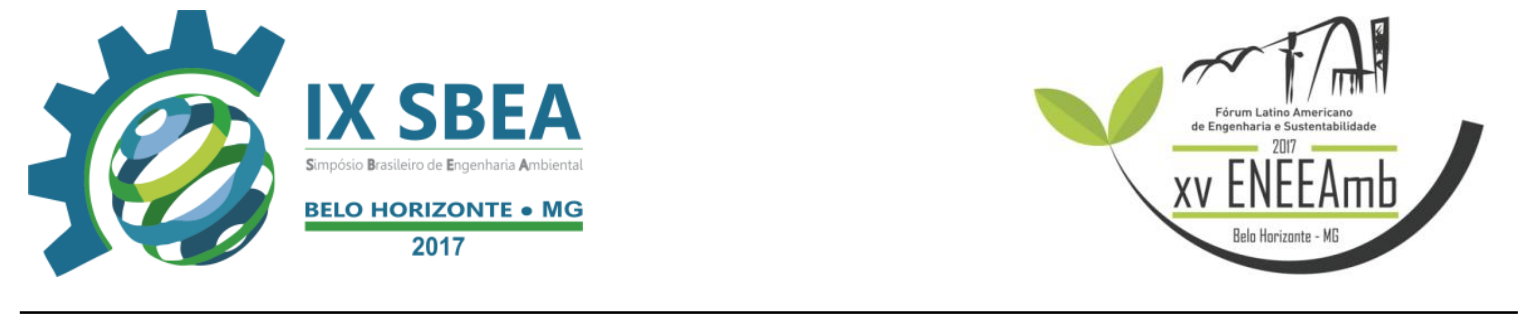

\section{Carta índice da Bacia Hidrografica do Rio Paraopeba}

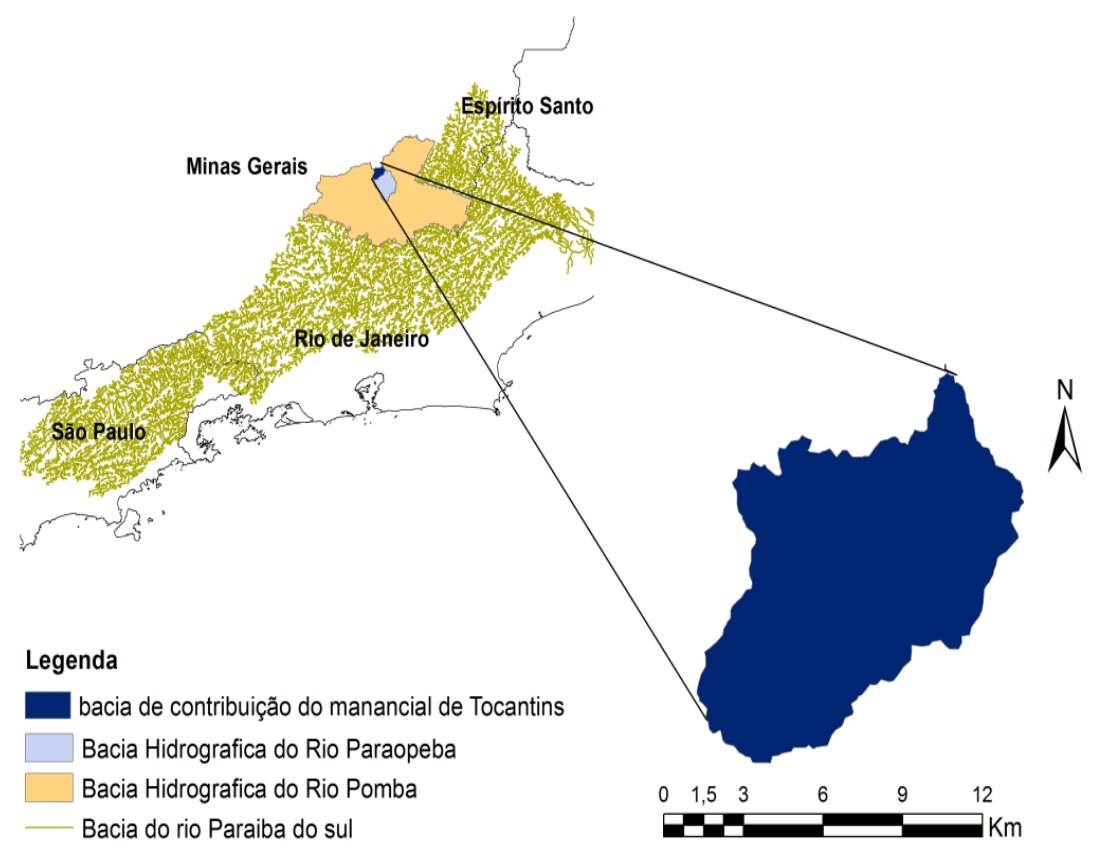

Figura 1:Carta índice da Bacia de contribuição do manancial

Utilizou-se imagens do produto do Landsat5 sensor TM (ThematicMAPPer), data de06/2003, e Landsat 8 sensor OLI, data de 07/2016.Ambos com orbita/ponto 217/75, resolução espacial de 30m e temporal de 16 dias. Para a escolha das imagens adotou-se como critério a cobertura de nuvens (Landasat5 com 20\% de cobertura e a Landsat 8 com 2,26\%) uma vez que essa condição interfere na classificação,além de escolher imagens na estações do ano. As imagens foram fornecidas gratuitamente pelo Departamento de geração de imagens DGI/INPE, georreferenciadas para o Datum WGS 1984, UTM, com fuso 23S e 23N, Landsat 5 e Landsat 8, respectivamente.

Previamente à classificação das imagens, foi realizado um georreferenciamento das imagens Landsat5 para eliminar erros geométricos utilizando uma imagem ortorretificada, fornecida pelo Instituto Nacional de Pesquisas Espaciais - INPE, através da ferramenta Map - resgitation: imagem to imagem. Para as imagens do produto Landsat 8 não houve necessidade de georreferenciá-las, porém foi necessário reprojetálas para o Hemisfério Sul.A partir das imagens já pré-processadas fez-se a composição das bandas RGB utilizando a ferramenta LayerStracking no programa ENVI 5.2®. 


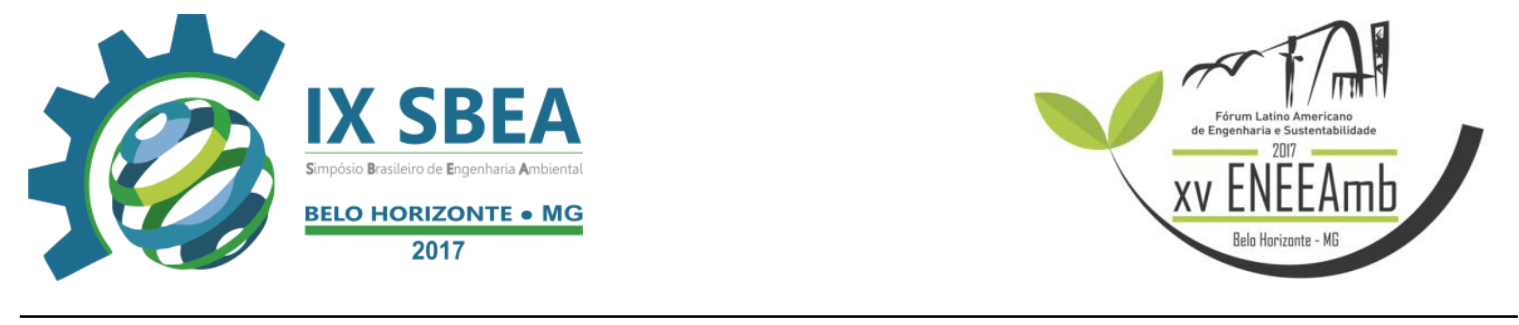

Através de visitas em campo para reconhecimento da área e da ferramenta Google EarthPro foram escolhidas três classes, sendo elas, pastagem, solo exposto e vegetação (matas), que predominam na bacia. Apesar de existirem pequenos córregos e lagos, além de uma área urbana de baixa densidade na bacia, estas classes não foram consideradas, pois são muito pouco expressivas e não são bem representadas devido à baixa resolução da imagem utilizada.

Para o uso e ocupação do solo empregou-se a classificação supervisionada, no software ENVI 5.2®, aplicando o método da Maximaverosemelhança, que verifica a probabilidade de um pixel pertencer a uma determinada classe tomando como base o Teorema de Bayes (RIBEIRO,2001).

Após a classificação das duas imagens gerou-se a matriz de erros, através da concordância das classificações com as áreas de treinamento, considerando áreas de validação para a comparação com as áreas classificadas. O intuito dessa etapa foi verificar a exatidão das classificações, através da análise do índice KAPPA e dos erros de comissão e omissão.

Em seguida, realizou-se o corte das imagens através da criação de máscara da área de drenagem da bacia em estudo, utilizando a ferramenta Masking do ENVI 5.2®.

Para comparar as mudanças ocorridas no uso e ocupação do solo no decorrer desses 13 anos na área estudada, utilizou-se a ferramenta do ENVI 5.2® de detecção de mudanças por estatística.

Objetivando avaliar a vulnerabilidade das áreas de preservação permanentes, realizaram-se os Buffers dos cursos d'água e das nascentes. A bacia é composta por córregos e rios com extensão menor que 10 metros, foram construídos buffers de 30 metros correspondendo ao limite mínimo de preservarão das matas ciliares para essa extensão de rios e buffers de 50 metros para as nascentes, conforme preconiza o novo Código Florestal. Esses foram executados através de dados vetoriais da hidrografia da área fornecidos pelo IBGE utilizando a ferramenta Buffer do software Arcgis 10.0®.

\section{RESULTADOS E DISCUSSÕES}

As Figuras 2 e 3 representam os mapas de uso e ocupação do solo da bacia para os anos de 2003 e 2016. 

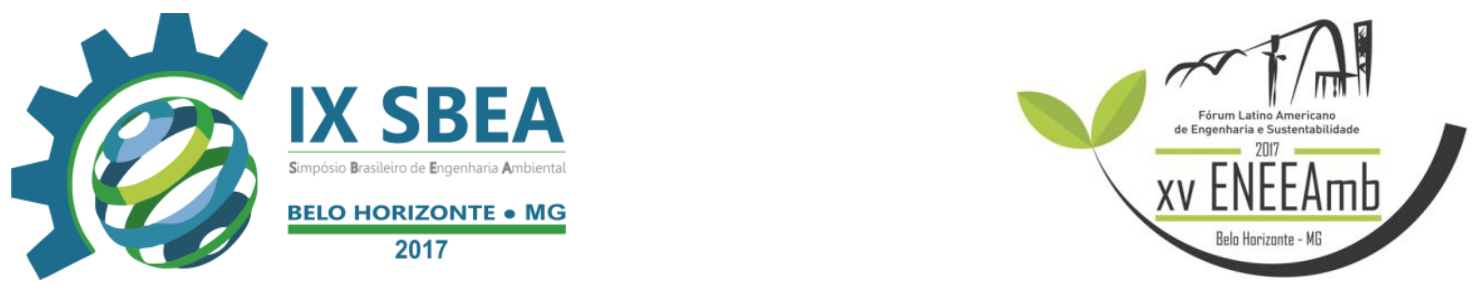

Uso e ocupação do solo da bacia de contribuição do manancial de Tocantins-MG, anos de 2003

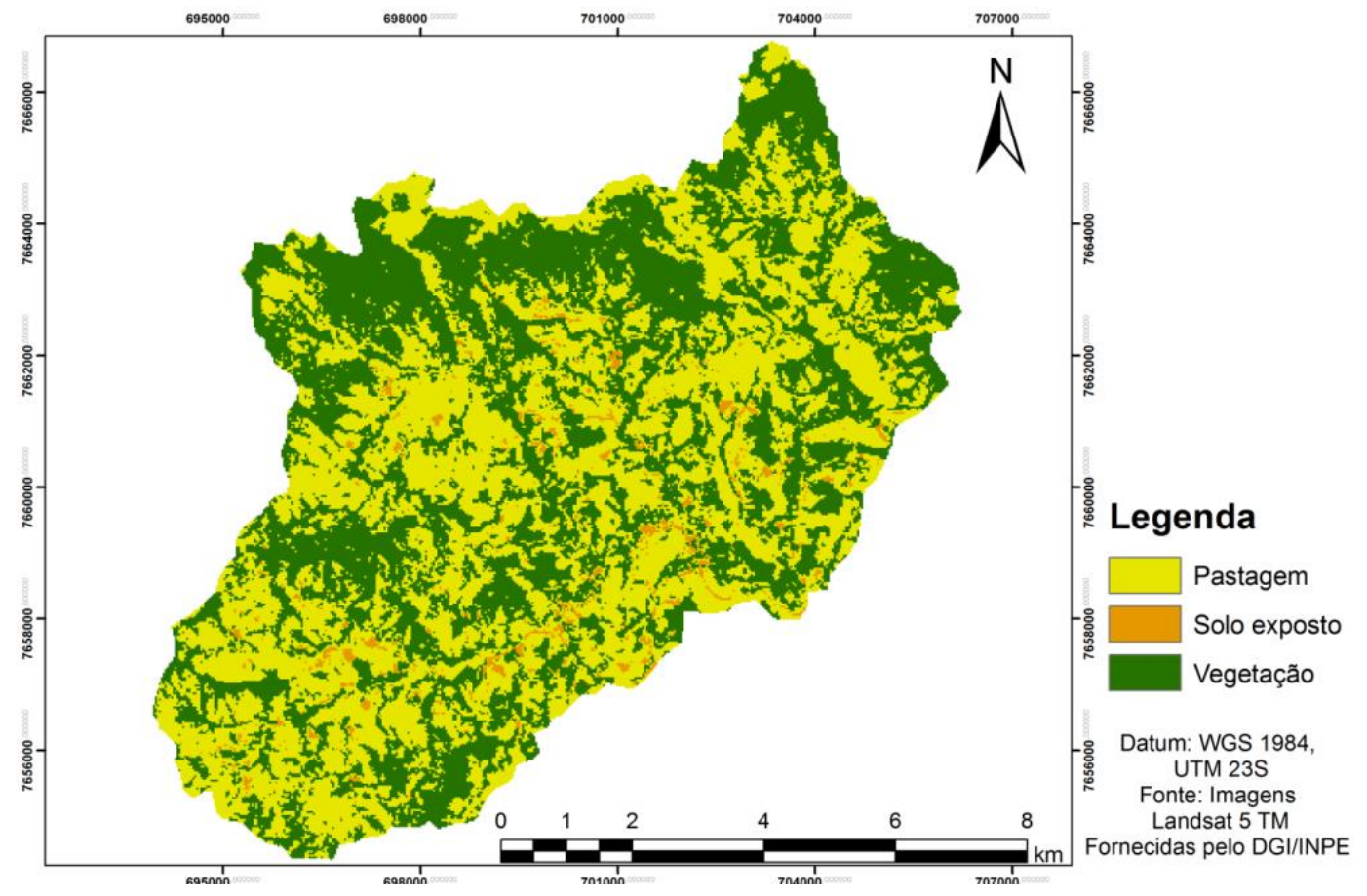

Figura 2:Uso e ocupação do solo do manancial de Tocantins para o ano de 2003

Uso e ocupação do solo da bacia de contribuição do manancial de Tocantins-MG, anos de 2016

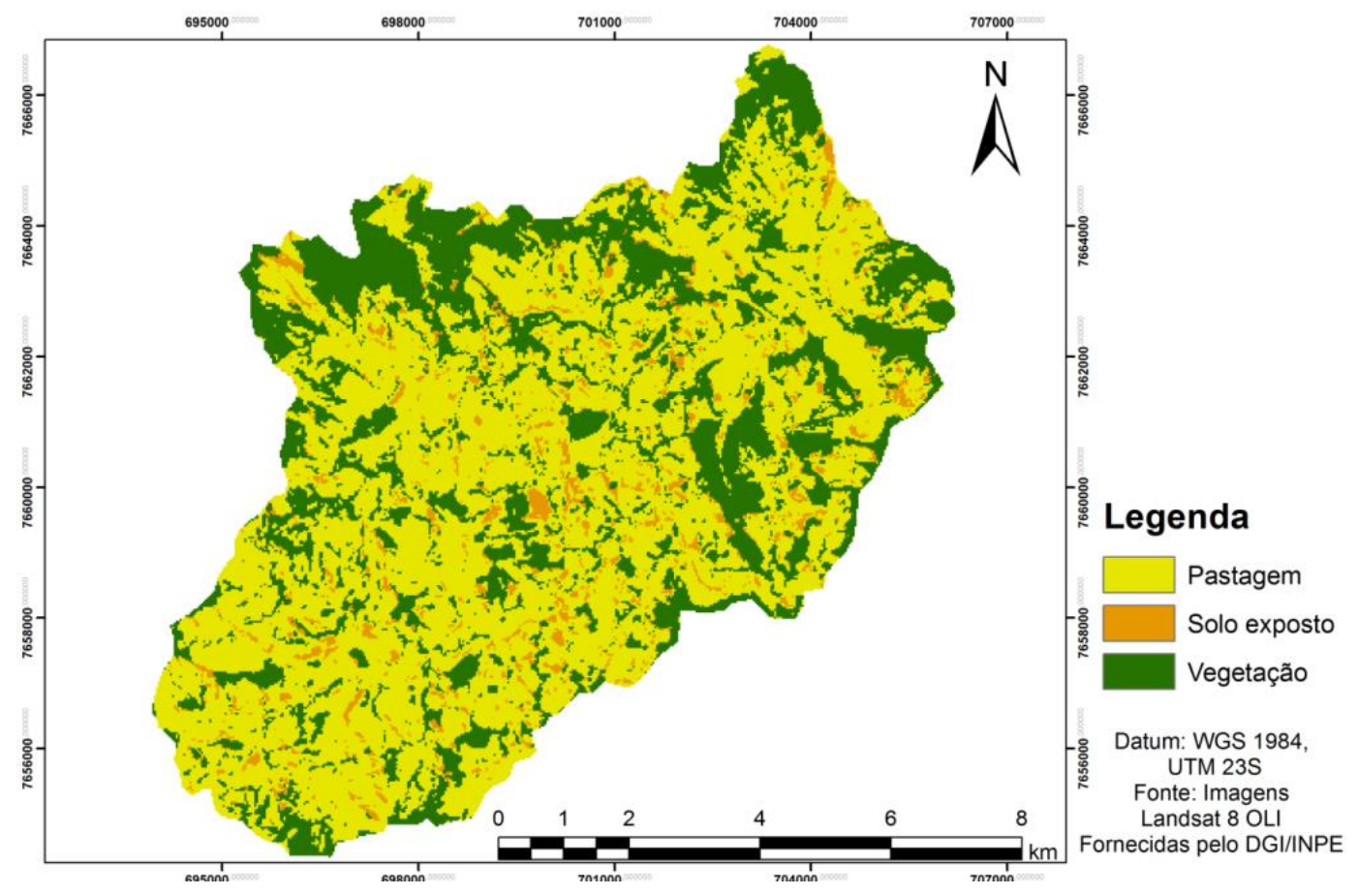

Figura 3:Uso e ocupação do solo do manancial de Tocantins para o ano de 2016

IX Simpósio Brasileiro de Engenharia Ambiental, XV Encontro Nacional de Estudantes de 


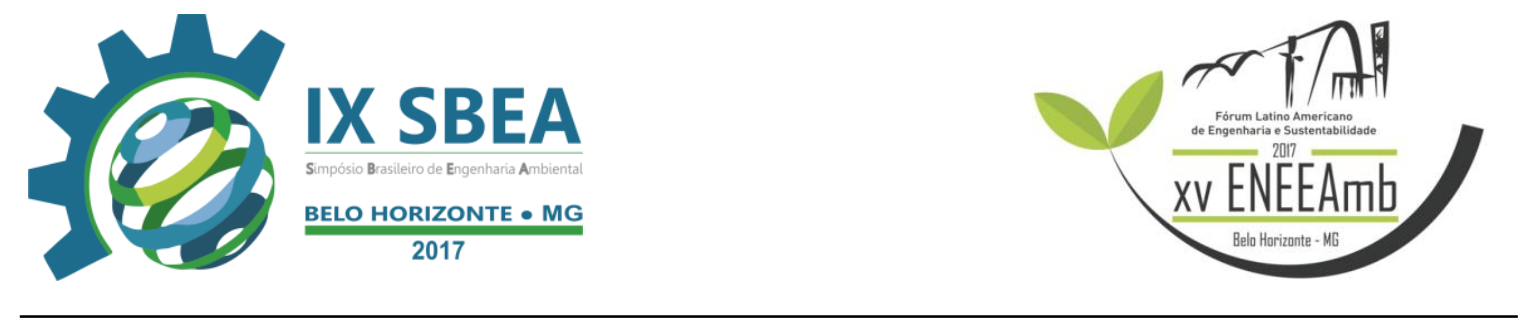

A matriz de erro aplicada a estas duas cartas resultou em um coeficiente KAPPA de $98 \%$ a 99\%, respectivamente, resultando assim em baixos erros de comissão e omissão, apresentando uma concordância muito boa com as áreas de validação. Demonstrando a confiabilidade das classificações feitas para as áreas estudadas.

Através das Figuras 2 e 3 é possível identificar as mudanças que ocorreram nessa bacia, no período considerado. É notável nas cartas de uso e ocupação do solo, o aumento da área de pastagem e solo exposto em detrimento da vegetação (matas), demonstrando a exploração desordenada do solo. Verifica-se, que a bacia de contribuição do manancial de Tocantins, localizada na zona rural do município, é composta principalmente por atividades agropecuárias e como essas necessitam retirar a vegetação natural para implantar suas atividades, geram a degradação da área.

Os resultados da análise estatística apresentada na Figura 4 confirmam a mudança visual do uso do solo com o passar dos anos e apresentam quais foram essas principais transformações.

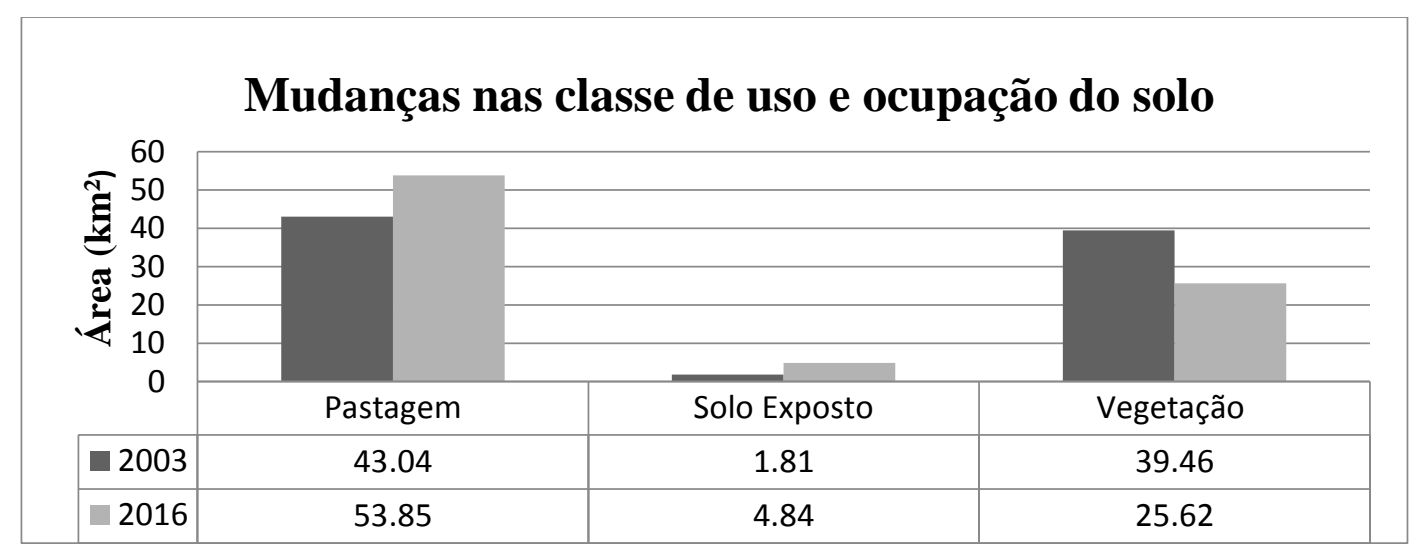

Figura 4: Áreas $\left(\mathrm{km}^{2}\right)$ do uso e ocupação do solo para a bacia de contribuição do manancial

A classe pastagem apresentou um aumento considerável $\left(10,81 \mathrm{~km}^{2}\right)$, para o período de tempo estudado. Em 2003 a pastagem ocupava 51\% da área total, já em 2016 passou a ocupar $64 \%$ da área da bacia. O solo exposto aumentou em $4 \%$ a sua representação na área da bacia nesse período de 13 anos.

A classe vegetação (matas) foi amplamente modificada, no ano de 2003 possuíam39,46 km² (47\% da área total da bacia), desses 55,3\% foram convertidos em 


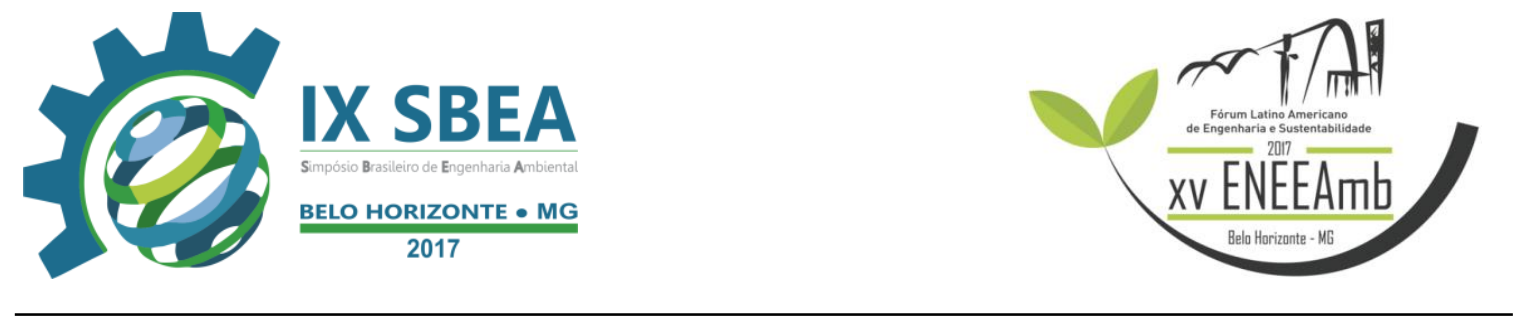

pastagem, 5,8\% viraram solo expostos e somente 38,8\% permaneceram preservados, resultando em uma área remanescente de 25,62 km² em 2016, correspondendo,em 2016,a 30\% da área total da bacia. A degradação da vegetação não foi tão alarmante, pois houve transformações das outras classes para essa, a pastagem mudou $23 \%$ para vegetação (matas) e o solo exposto $20 \%$, porém o reflorestamento dessas classes possivelmente está relacionado a espécies não oriundas da região.

Segundo BOLIN \&COOH(1983), apud TOLEDO (2001), esse desmatamento acompanhado do aumento das áreas de pastagem e solo exposto, alteram o balanço hídrico, pois diminuem a infiltração do solo e aumentam o escoamento superficial, podendo causar reflexos nas camadas superficiais, com ocorrência de erosão, transporte de sedimentos, assoreamento dos rios, modificações na qualidade da água, entre outros.

As Figuras 5 e 6 mostram como as áreas de APP, na bacia, foram degradadas com o passar dos anos. Comparativamente com a Figura 5, percebe-se que na imagem 6, ano de 2016, as matas ciliares e as nascentes estão mais desprotegidas, desrespeitando o Código Florestal (Lei no 12.651, de 25 de maio de 2012). Isso pode acarretar na diminuição da proteção dos corpos d'água, aumento da poluição das águas e assoreamento dos rios, além de prejudicar a recarga de aquíferos e comprometer o abastecimento público de água em qualidade e em quantidade. (BRASIL, 2017). 

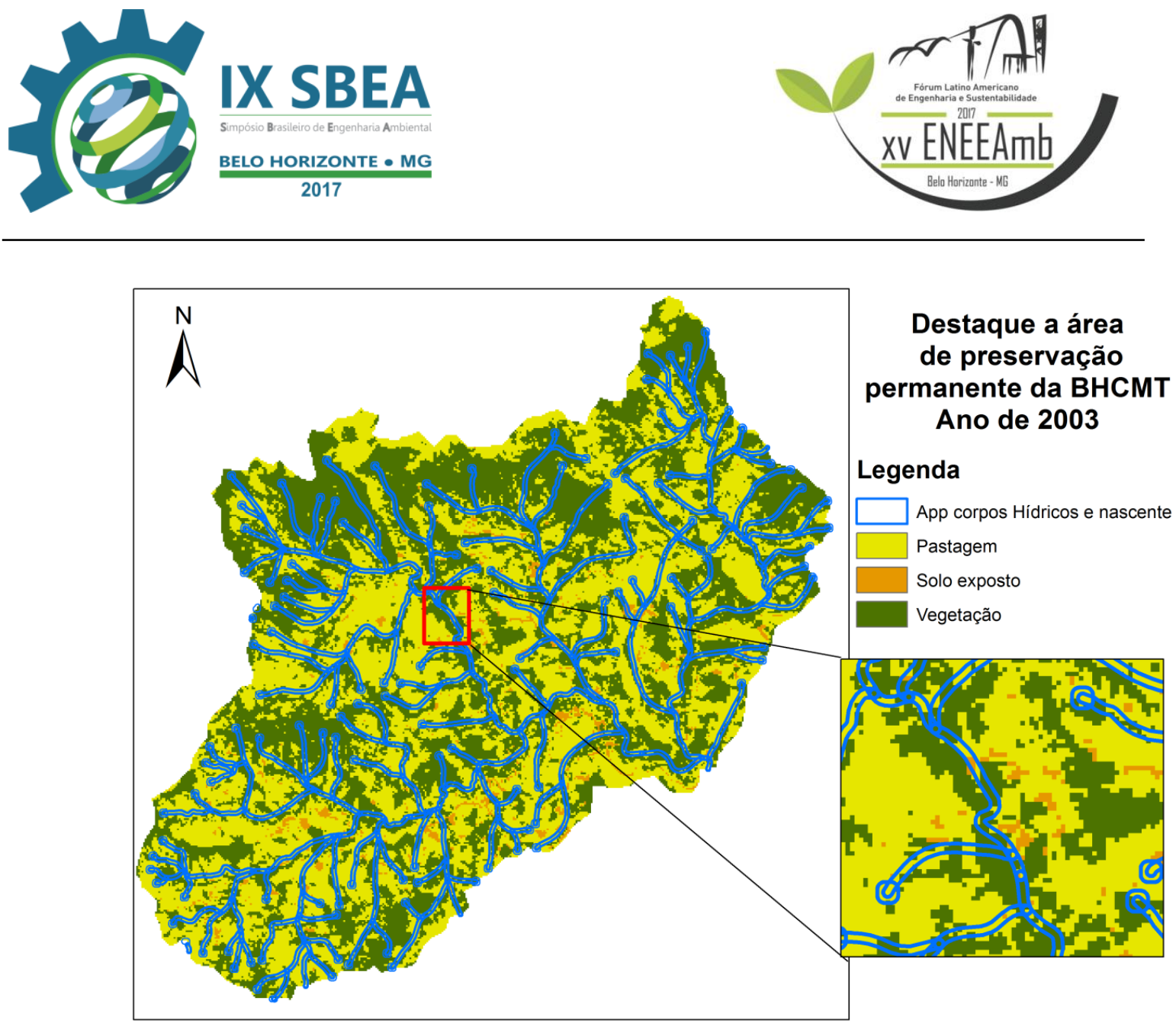

Figura 5:Destaque a APP para o ano de 2003, na Bacia hidrográfica de contribuição do manancial de Tocantins (BHCMT)

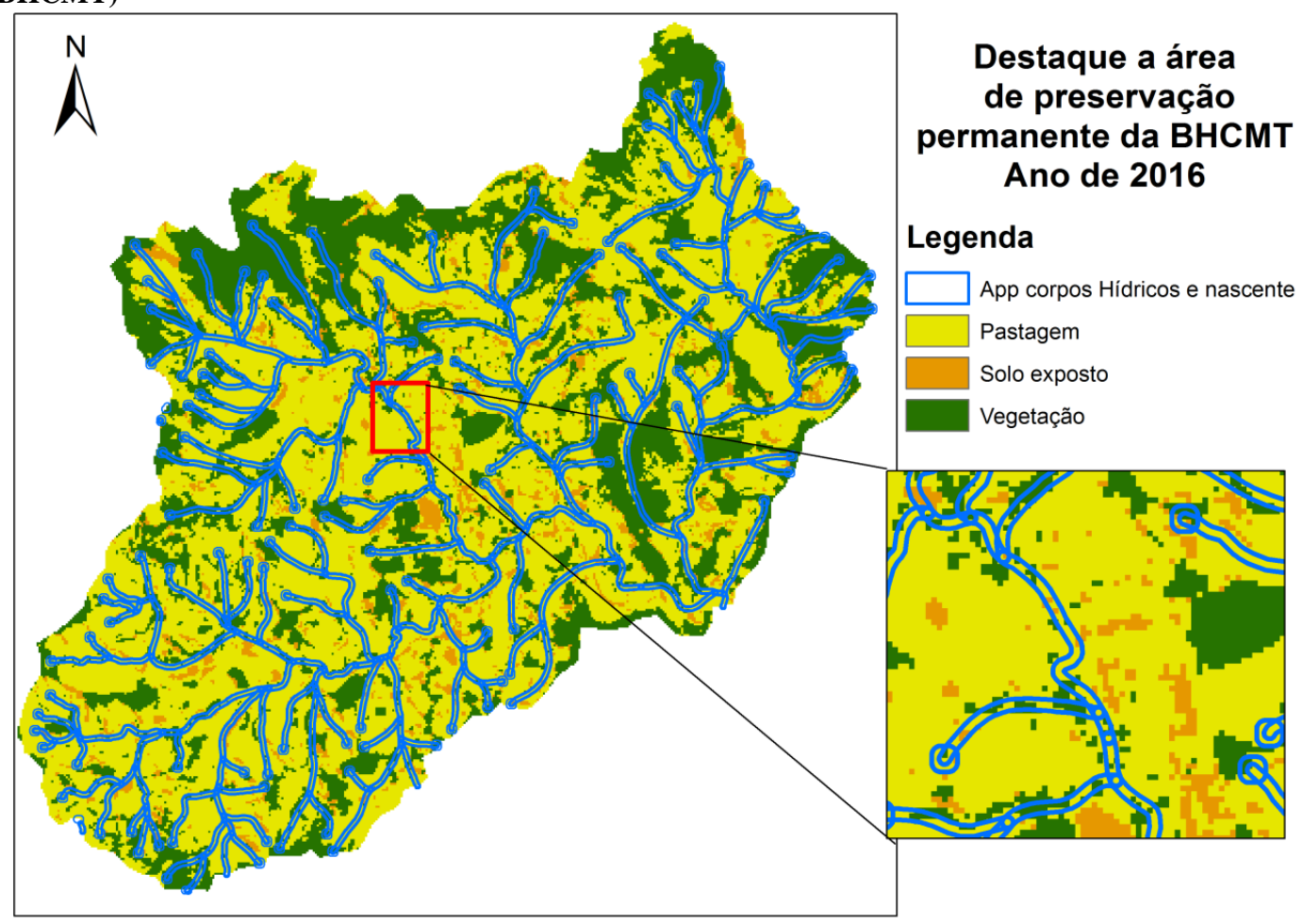

Figura 6:Destaque a APP para o ano de 2016, na Bacia hidrográfica de contribuição do manancial de Tocantins (BHCMT) 


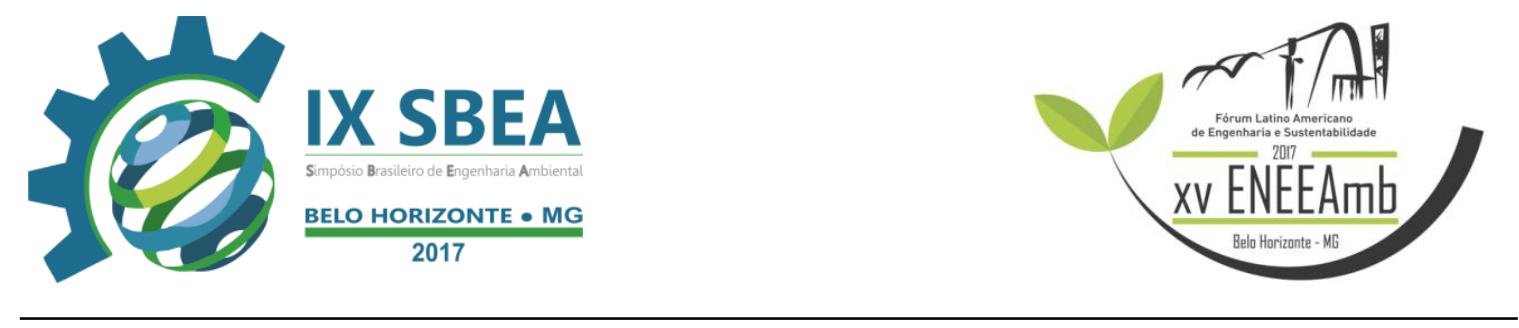

A tabela 1 apresenta as áreas de ocupação do solo nas áreas de APP para os anos de 2003 e 2016. Destaca-se o decréscimo das áreas de vegetação (matas) e o aumento das áreas de pastagens nessas áreas.

Tabela 1: Áreas de ocupação do solo nas áreas de APP, na Bacia hidrográfica de contribuição do manancial de Tocantins (BHCMT)

\begin{tabular}{|c|c|c|c|}
\hline Ano & Pastagem $\left(\mathbf{k m}^{\mathbf{2}}\right)$ & Solo Exposto $\left(\mathbf{k m}^{\mathbf{2}}\right)$ & Vegetação $\left(\mathbf{k m}^{\mathbf{2}}\right)$ \\
\hline 2003 & 5,38 & 0,22 & 6,10 \\
\hline 2016 & 7,57 & 0,59 & 3,56 \\
\hline
\end{tabular}

\section{CONCLUSÃO}

Os efeitos causados pela falta de conservação e proteção em bacias hidrográficas de mananciais de abastecimento podem gerar consequências indesejáveis na qualidade e na quantidade hídrica, contribuindo para uma degradação ambiental. Os mananciais são fonte de água para o abastecimento, dessa forma deve ser preservada a área de sua bacia de contribuição, a fim de garantir a qualidade de água para abastecimento da população, e consequentemente diminuir a complexidade e os custos com o tratamento.

O estudo temporal do uso e ocupação do solo permitiu monitorar as alterações ocorridas na bacia de contribuição do manancial da cidade de Tocantins (MG), mostrando que houve um acentuado desmatamento e aumento da pastagem, e como essas podem afetam as áreas de APP e consequentemente a qualidade da água do manancial. Esses resultados demonstram como as técnicas de sensoriamento remoto são ferramentas potenciais para o monitoramento ambiental e gerenciamento dos recursos hídricos.

\section{REFERÊNCIAS BIBLIOGRÁFICAS}

BRASIL. Ministério do meio ambiente. áreas de preservação permanente urbanas. disponível em: <http://www.mma.gov.br/cidades-sustentaveis/areas-verdesurbanas/áreas-de-proteção-permanente>. acesso em: 27 maio 2017 


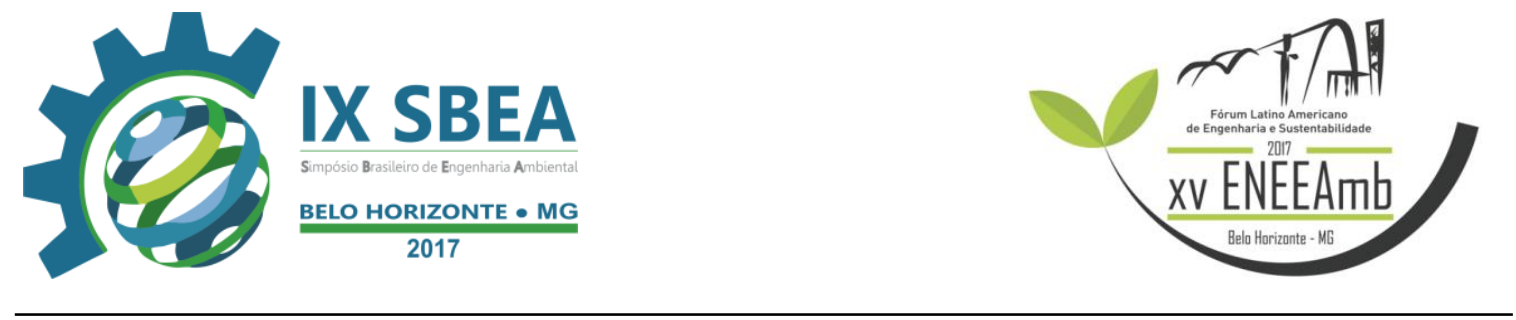

IBGE - Cidades. disponível em: <http://cidades.ibge.gov.br/xtras/home.php>. acesso em: 18 abr. 2017.

LOPES, F. MIELNICZUK, J. , ELISANDRA S. O. Evolução do uso do solo em uma área piloto da região de vacaria, rs1. revista brasileira de. engenharia agrícola e ambiental, campina grande, pb, uaea/ufcg, v. 14, n. 10, p. 1038-1044, jul. 2010

MARGALEF, R. Limnologia. Barcelona: Omega, 1983. 100 p.

PORTO, M. F A. Gestão de bacias hidrográficas. estudos avançados, v. 22, n. 63,p. 43-60, são paulo 2008. http://www.scielo.br/scielo.php?script=sci_arttext\&pid=s01030142008000200004\&lng=pt\&nrm=iso\&tlng=pt. acesso em: 17 abr. 2017.

RIBEIRO, C. B. DE M. R. Sensoriamento remoto aplicado à detecção de mudanças na cobertura do solo de uma bacia hidrográfica. 2001. 206 f. dissertação (mestrado) - curso de ciências em engenharia civil., universidade federal do rio de janeiro, rio de janeiro, 2001.

SOPPER, W. E. Effects of timber harvesting and related management practices on water quality in forested watersheds. Journal of Environmental Quality, Madison, v.4, n.1, p.24-9, 1975

TOLEDO, L. G.; NICOLELLA, G. Índice de qualidade de água em microbacia sob uso agrícola e urbano, Scientia Agrícola, v.59, n. 1, p. 181-186. 2002. 